\title{
Duodenal Neoplasm
}

National Cancer Institute

\section{Source}

National Cancer Institute. Duodenal Neoplasm. NCI Thesaurus. Code C2995.

A benign or malignant neoplasm that affects the wall of the duodenum. Representative examples include adenoma, carcinoma, and lymphoma. 